\title{
Synchronous primary sigmoid colon cancer and primary thyroid cancer followed by a malignant tumor of the kidney: Case report of multiple primary cancer and review of the literature
}

\author{
CHENG PENG ${ }^{1,2}$, ZEQUN LI $^{1,2}$, HUIJIE GAO $^{1,2}$, XUEQING ZOU $^{1,2}$, \\ XIAO WANG ${ }^{3}, \mathrm{CHANGKUO} \mathrm{ZHOU}^{4}$ and $\mathrm{JUN} \mathrm{NIU}^{1,2}$ \\ ${ }^{1}$ Department of Hepatobiliary Surgery, Qilu Hospital of Shandong University; \\ ${ }^{2}$ The Institute of Laparoscopic Minimally Invasive Surgery, Department of Hepatobiliary Surgery, \\ Shandong University; ${ }^{3}$ Department of Pathology, Qilu Hospital of Shandong University; \\ ${ }^{4}$ Department of Urology Surgery, Hospital of Shandong University, Jinan, Shandong 250012, P.R. China
}

Received March 6, 2018; Accepted November 13, 2018

DOI: $10.3892 / \mathrm{ol} .2018 .9867$

\begin{abstract}
Multiple primary cancer (MPC) is relatively rare. With the development of diagnostic and anti-cancer therapeutic techniques, the incidence of MPC is rising annually. However, the incidence of triple or quadruple cancers in a single patient remains low. In this report, the case of a 58-year-old male with triple malignant cancer is outlined. Synchronous sigmoid colon cancer and thyroid cancer were diagnosed in May 2015; on subsequent re-examination, metastasis to the liver and a malignant kidney tumor were also identified. The diagnosis was established via computed tomography (CT), Positron emission tomography-CT (PET-CT) and other laboratory examination results, including analysis of tumor markers and liver function, and was confirmed by pathological diagnosis. The patient underwent radical surgery and standardized chemotherapy. Through literature review, the definition, characteristics, classification, incidence, possible causes of and treatment strategies for MPC were more clearly understood. In addition, immunohistochemical staining of integrin $\alpha v \beta 6$ was performed on patient tissue specimens, where integrin $\alpha v \beta 6$ expression was confirmed in cancer of the colon, thyroid and liver, as a result of colonic metastasis. Therefore, the involvement of integrin $\alpha v \beta 6$ in the malignant progression of MPC was hypothesized, which may aid the investigation of MPC etiology in the future.
\end{abstract}

\section{Case report}

In October 2016, a 58-year-old male patient was referred to the Hepatobiliary Department of Qilu Hospital (Jinan, China)

Correspondence to: Dr Jun Niu, Department of Hepatobiliary Surgery, Qilu Hospital of Shandong University, 44 Wenhuaxi Road, Jinan, Shandong 250012, P.R. China

E-mail: qlniujun@163.com

Key words: multiple primary cancer, integrin $\alpha \mathrm{v} \beta 6$ for review. The patient had previously been diagnosed with sigmoid cancer (first primary) and left lobe thyroid cancer (second primary) in May 2015. A left hemicolectomy and radical surgery were undertaken for the thyroid cancer. The final pathology results for sigmoid colon cancer revealed well-differentiated adenocarcinoma, polypus type, incisal surface square $2.8 \times 0.3 \mathrm{~cm}$, and invasion of the stratum sub-mucosa. There were no carcinoma cells at the anodic and bottom incisal margin, and no metastasis to the lymph nodes (Fig. 1A). The final pathology results for thyroid cancer revealed left lobe micro-papillary carcinoma, and right lobe lymphatic nodule thyroiditis (Fig. 1B). As the sigmoid colon cancer was in the early stages (pT1, pN0, M0; Stage I), adjuvant chemotherapy was not administered; $3 \mathrm{x}$ cantharidis capsules were taken twice daily, for 11 months. Routine, post-surgical, examination, including blood tests, abdominal and pelvic CT scans, and a colonoscopy were performed. Tumor marker analysis indicted that carcinoembryonic antigen (CEA) $(230.10 \mathrm{ng} / \mathrm{ml})$, cancer antigen (CA)-199 (89.23 U/ml) and CA-724 (8.80 U/ml), and neuron-specific enolase (NSE) (21.68 ng/ml), among other markers, including CYFr21-1, squamous cell carcinoma antigen, pro-gastrin releasing peptide, $\alpha$-fetoprotien, CA-125, Ferrari, total prostate-specific antigen and serum sialic acid were within the normal range. CT scan suggested that, according to the patient history, the space-occupying lesion located in the V and VIII liver segments may have been the metastatic tumor; the VII segment tumor may have been an hemangioma (Fig. 2A and B); and the space-occupying lesion of the right kidney anus perineum may have been primary kidney cancer (third primary) (Fig. 2C and D).

The colonoscopy results were satisfactory, with no recurrence noted (Fig. 2E). To further investigate the characteristics of the liver and kidney tumors, PET-CT examination was conducted, the results of which indicated that: i) The tumor in the right anterior lobe of the liver may have been a metastatic lesion (Fig. 3A); ii) combined with the CT scan results, it was supposed that the tumor of the right kidney anus perineum may have been malignant (hypo-metabolism type) (Fig. 3B); iii) 1.5 years after radical surgery for left lobe thyroid cancer, 
no recurrence was observed (Fig 3C); iv) a small node in the left anterior-inferior abdominal exhibited high absorbance of FDG, possibly indicating metastasis or a responsive modification (Fig. 3D).

As a result of these findings, surgical excision of the metastatic liver tumor and hepatic hemangioma, in addition to a partial nephrectomy, were conducted on October 11th, 2016 (Fig. 4). The final pathology examination results revealed: i) $\mathrm{V}$ and VIII segment liver, well-differentiated adenocarcinoma in the liver tissue (incision square, $4.0 \times 2.7 \mathrm{~cm}$ ), which, according to the patient history, is the metastatic tumor from the primary colon cancer (Fig. 1C); ii) VII segment liver, cavernous hemangioma; iii) kidney, clear-cell carcinoma of the kidney (II level nuclear) with a diameter of $2.3 \mathrm{~cm}$ (Fig. 1D); iv) abdominal wall, hyperplastic collagen fiber and vascular tissue. Post-surgery, the patient recovered well, and was administered one course of FOLFORX6 chemotherapy prior to discharge (November 3rd, 2016). In subsequent follow-up, the patient had recovered markedly.

For resected specimens of colon, thyroid, liver metastatic tumor and renal cell carcinoma, immunohistochemical staining of integrin $\alpha v \beta 6$ was performed, the results of which are detailed below. Experimental methods were as follows: Mouse anti-human monoclonal antibody (clone 6.2A1; IgG1) against integrin $\alpha v \beta 6$ was obtained from Biogen (Abcam, Cambridge, MA, USA). Patient tissue sections were deparaffinized and hydrated, and heat-induced epitope retrieval was performed using Borg decloaking high $\mathrm{pH}$ buffer in the Biocare decloaking chamber (Biocare Medical, LLC, Pacheco, CA, USA). Endogenous peroxidase activity was blocked with $3 \%$ hydrogen peroxide for $5 \mathrm{~min}$ at room temperature. The slides were incubated with an Endogenous Avidin-Biotin Blocking kit (cat. no. ab64212; Abcam) for 10 min, followed by further incubations with the integrin $\alpha v \beta 6$ primary antibody 6.2A1 (1:500) overnight at $4^{\circ} \mathrm{C}$. The following day, biotinylated anti-mouse IgG (1:200; cat. no. ab207996; Abcam) was applied to the slides for $20 \mathrm{~min}$ at $37^{\circ} \mathrm{C}$, which were subsequently treated with $50 \mu \mathrm{l}$ horseradish peroxidase-labeled streptoantibiotin (Dako; Agilent Technologies, Inc., Santa Clara, CA, USA) for $15 \mathrm{~min}$ at $37^{\circ} \mathrm{C}$ and Betazoid Diaminobenzidine (Biocare Medical, LLC, Pacheco, CA, USA) for color development for $2 \mathrm{~min}$ at room temperature. The slides were counterstained with hematoxylin for $1 \mathrm{~min}$ (Dako; Agilent Technologies, Inc.), rinsed with water for $2 \mathrm{~min}$, and dehydrated with alcohol and xylene for several seconds, before a coverslip was affixed. Normal mouse IgG (1:200; cat. no. ab188776; Abcam) was substituted for primary antibody as the negative control and incubated with the slides overnight at $4^{\circ} \mathrm{C}$. Unless otherwise indicated, incubations were performed at room temperature. On all slides, $>5 \%$ of the cells stained positively for integrin $\alpha v \beta 6$.

\section{Discussion}

MPC refers to the presence of $\geq 2$ pathologically diagnosed primary cancers, in $\geq 1$ organ of the same patient. The diagnosis of MPC is based on the Warren standards (1): i) All tumors identified after the pathological examination are malignant; ii) each tumor is independent of the others, and the possibility of transfer is excluded; and iii) all tumors originate from different organs. According to differences in primary tumor occurrence times, simultaneous MPC refers to cases wherein all tumors appear within 6 months; otherwise, it is known as non-simultaneous or metachronous MPC.

MPC is relatively rare, with a reported incidence range of 0.8-6.6\% among the general population (2-4); however, the Surveillance Epidemiology and End Results report issued by the National Cancer Institute states that between 1975 and 2000 , the incidence increased to $\sim 16 \%$ (5). This difference may be associated with location, environment, living habits, quality and availability of medical care, the type of cancer and statistical research methods. The incidence of triple or quadruple malignant cancer in one patient remains rare, with the incidence of quadruple cancer reported to be $<0.1 \%(6-8)$. Thus, cases of MPC may be overlooked or misdiagnosed. MPC typically originates in pairs of organs or same system organs, such as the gastrointestinal, respiratory or urological systems. Male patients have an increased tendency to develop gastrointestinal cancer, and female patients are more prone to breast and gastrointestinal cancer $(9,10)$. Therefore, when a patient presents with these particular cancer types, clinicians should investigate whether an accompanying malignancy has occurred elsewhere. Baigrie (11) reported that colon cancer is frequently present in cases of MPC, particularly in patients between 50 and 60 years of age.

The definite cause of MPC is not clear. Though there are a number of factors that may influence its occurrence (including smoking, and exposure to carcinogens or carcinogenic environments) there are numerous defining characteristics of MPC. With improvements in living standards and medical technology, life expectancy is increasing, in accordance with the probability of acquiring a malignancy. It was reported by Curtis et al (12) that patients with cancer were $14 \%$ more likely to develop an additional tumor compared with the general population. Additionally, it was deduced by Jiao et al (6) that this phenomenon was associated with increased genetic instability, and the reduction of tumor immunity in cancer patients.

In addition, the wide application of diagnostic imaging has led to increased radiation exposure; this is particularly prominent in developed countries (13), where during routine follow-up examinations, patients are exposed through imaging procedures including X-rays and CT scans (14). Frequent doses of radiation may increase the occurrence of further malignancies (15). Studies have confirmed that the occurrence of head and neck cancer, particularly thyroid cancer, is associated with long-term radiological examination (16); specifically, the over-diagnosis and treatment of small adenocarcinoma was reported to influence the occurrence of thyroid cancer $(17,18)$. This is consistent with the case reported in the current study. Furthermore, the carcinogenic effects of chemotherapy and endocrine therapy may contribute to the development of MPC. For example, studies have demonstrated that in patients with breast cancer who received long-term treatment with tamoxifen or raloxifene, the incidence of endometrial cancer was increased 2-3-fold compared with healthy volunteers $(19,20)$.

Integrin $\alpha v \beta 6$ is an integrin subtype expressed only in epithelial cells; its primary ligand is fibronectin (FN). In healthy epithelial cells the expression of integrin $\alpha v \beta 6$ is rare (21), although it is increased substantially in response to injury and/or inflammation, and in epithelial tumors (including 
A

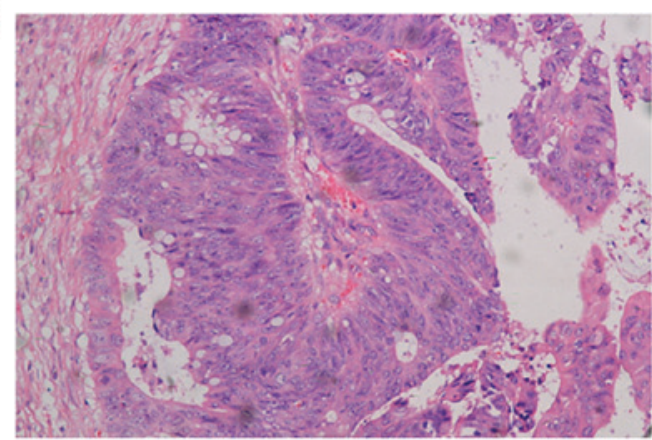

C



E

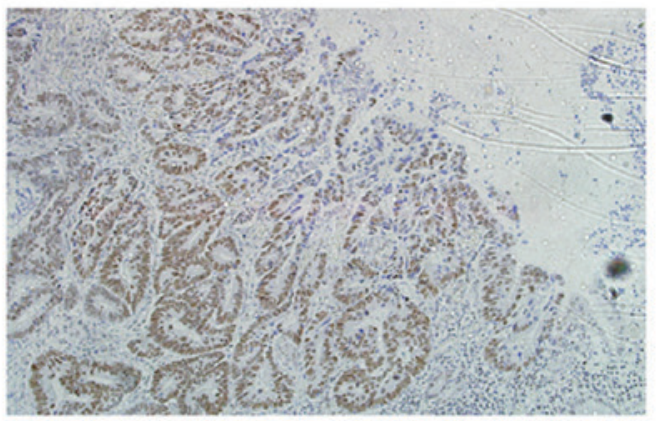

G

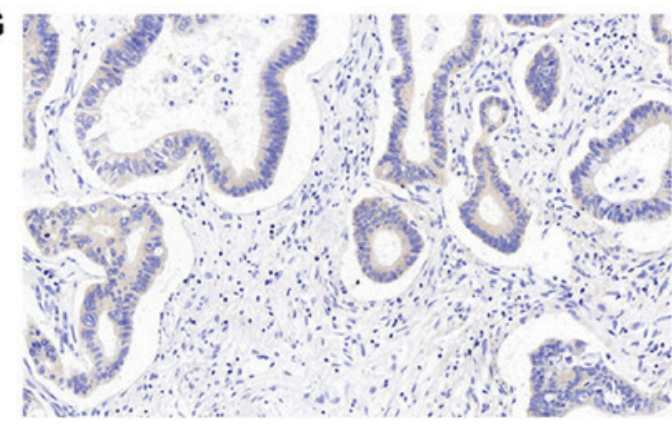

B

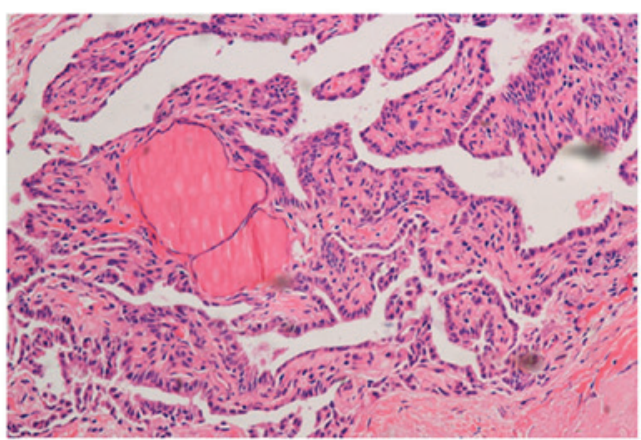

D

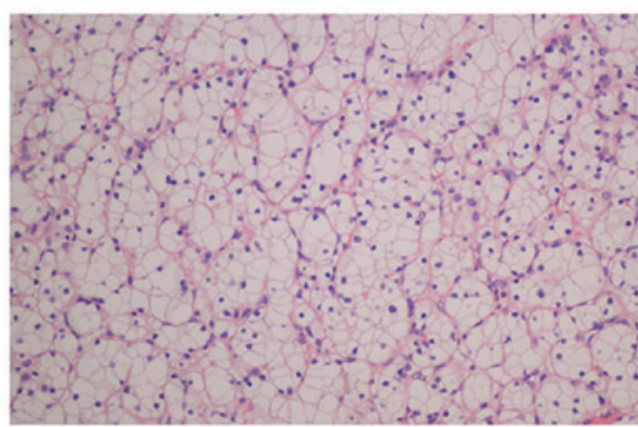

F

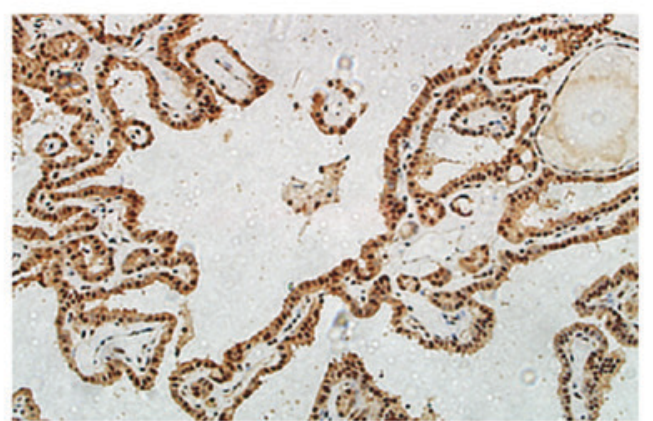

$\mathrm{H}$

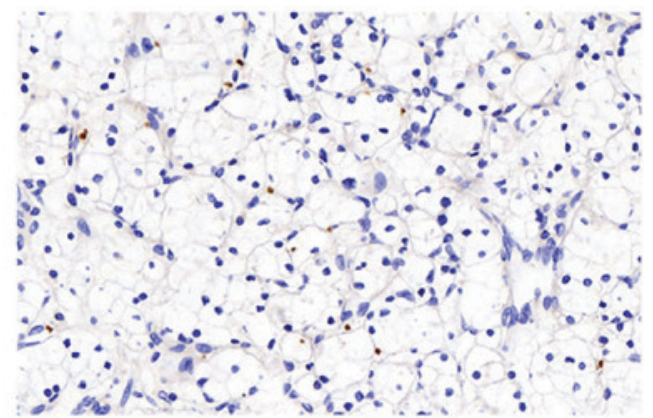

Figure 1. Tissue slice photomicrographs. (A) Hematoxylin and eosin stain photomicrograph of sigmoid colon cancer (magnification, x100). (B) Hematoxylin and eosin stain photomicrograph of left lobe thyroid micro-papillary carcinoma (magnification, x100). (C) Hematoxylin and eosin stain photomicrograph of differentiated adenocarcinoma in liver tissue (magnification, x200). (D) Hematoxylin and eosin stain photomicrograph of right kidney clear-cell carcinoma (magnification, x200). (E) Immunohistochemistry photomicrographs of positive integrin $\alpha v \beta 6$ staining in colon cancer tissue (magnification, x100). (F) Immunohistochemistry photomicrographs of positive integrin $\alpha v \beta 6$ staining in thyroid micro-papillary carcinoma tissue (magnification, x100). (G) Immunohistochemistry photomicrographs of positive integrin $\alpha v \beta 6$ staining in the hepatic metastatic tumor tissue (magnification, $x 200$ ). (H) Immunohistochemistry photomicrographs of negative integrin $\alpha v \beta 6$ staining in kidney clear-cell carcinoma tissue (magnification, $\mathrm{x} 400$ ). Integrin $\alpha v \beta 6$ staining was observed predominantly in the cell membrane. Positive $\alpha v \beta 6$ stained cells appeared with a brown appearance and negative stained cells appeared with a blue appearance, which was induced by hematoxylin stain.

gastric carcinoma and colon cancer) (22-24). The de novo expression of integrin $\alpha v \beta 6$ has been reported to modulate a number of characteristics of colon carcinoma cells, including adhesion and spreading on fibronectin, proliferation in collagen gels, tumor growth, invasion and metastasis, and apoptosis (25-28). In the present case report, immunohistochemical staining of integrin $\alpha v \beta 6$ was conducted, which revealed positive expression of integrin $\alpha v \beta 6$ in numerous tissues, including those from the colon cancer primary site (Fig. 1E), the left lobe of the thyroid (Fig. 1F), and the hepatic metastatic tumor (Fig. 1G). Expression of integrin $\alpha v \beta 6$ was negative in clear cell carcinoma of the kidney (Fig. $1 \mathrm{H})$. In a previous study, it 

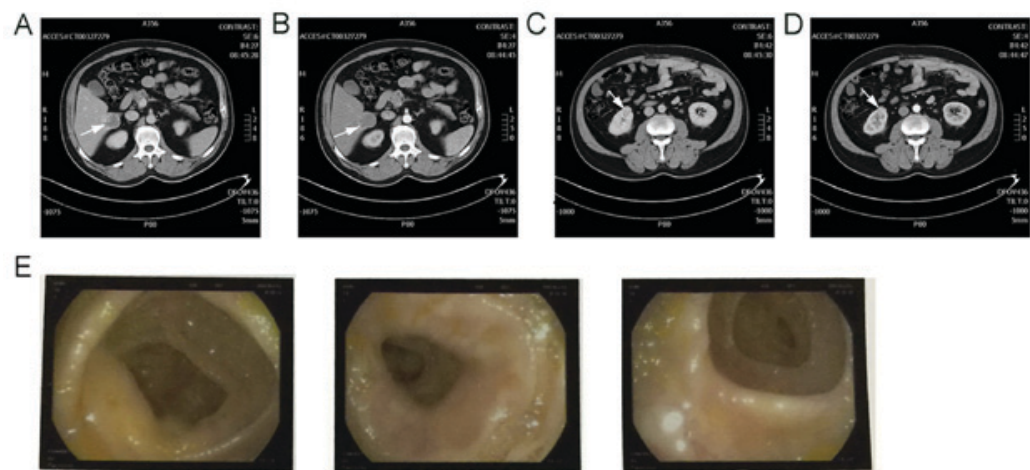

lleocecal valve Ascending colon

Transverse colon
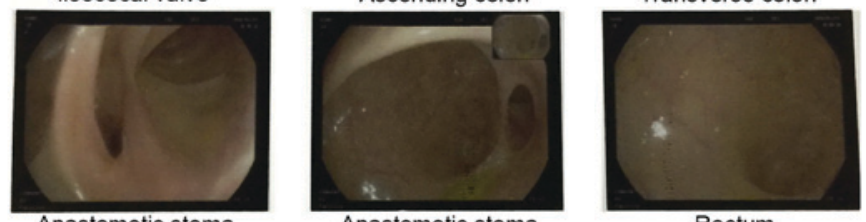

Anastomotic stoma

Anastomotic stoma

Rectum

Figure 2. Abdominal CT scan. Arrowhead refers to the location of the lesion. (A) Plain CT scan of liver hemangioma; (B) arterial phase CT scan of liver hemangioma; (C) plain CT scan of right kidney lesion; (D) arterial phase CT scan of right kidney lesion; (E) colonoscopy examination images. CT, computed tomography.

A


B

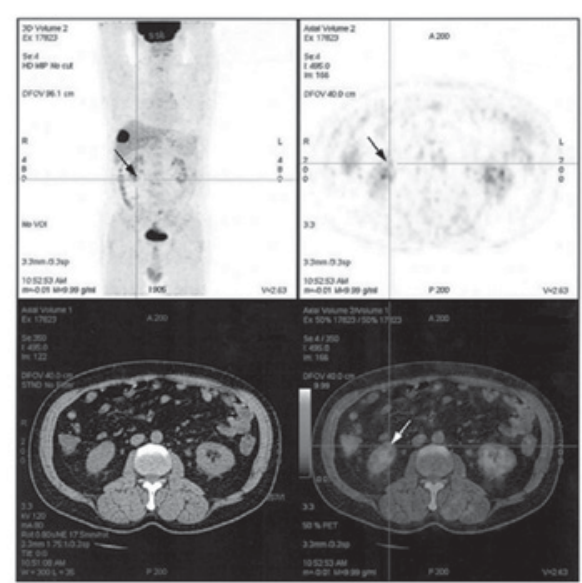

D



Figure 3. Whole body positron emission tomography-computed tomography scan. Arrowhead refers to the location of the lesion. (A) Hypo-metabolism lesion located in the right anterior lobe of the liver; (B) hypo metabolism lesion located in the right kidney anus perineum; (C) normal metabolism in the neck region with no recurrence of previous thyroid cancer; (D) slight hypo-metabolism of lesion located in the left anterior-inferior abdominal wall.

was identified that the rate of positive integrin $\alpha v \beta 6$ expression in hepatic metastatic foci was $71.4 \%$ (29). Our previous study regarding the associations between integrin $\alpha v \beta 6$ and thyroid cancer revealed the positive expression rate of integrin 


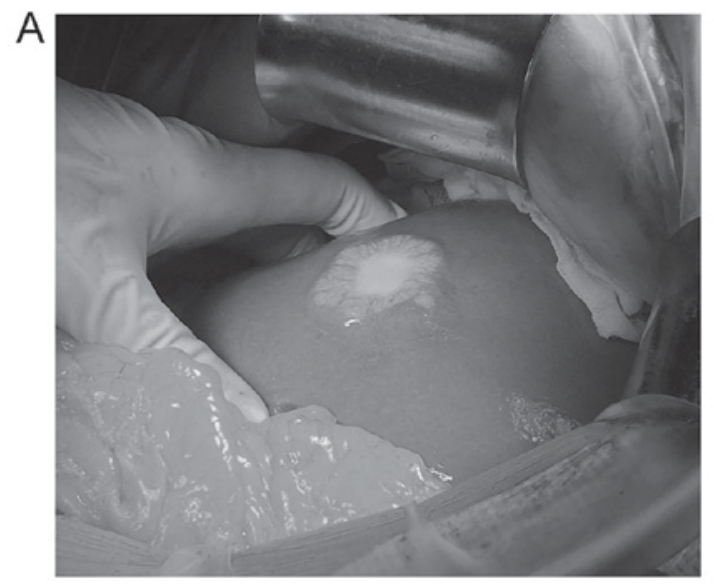

B
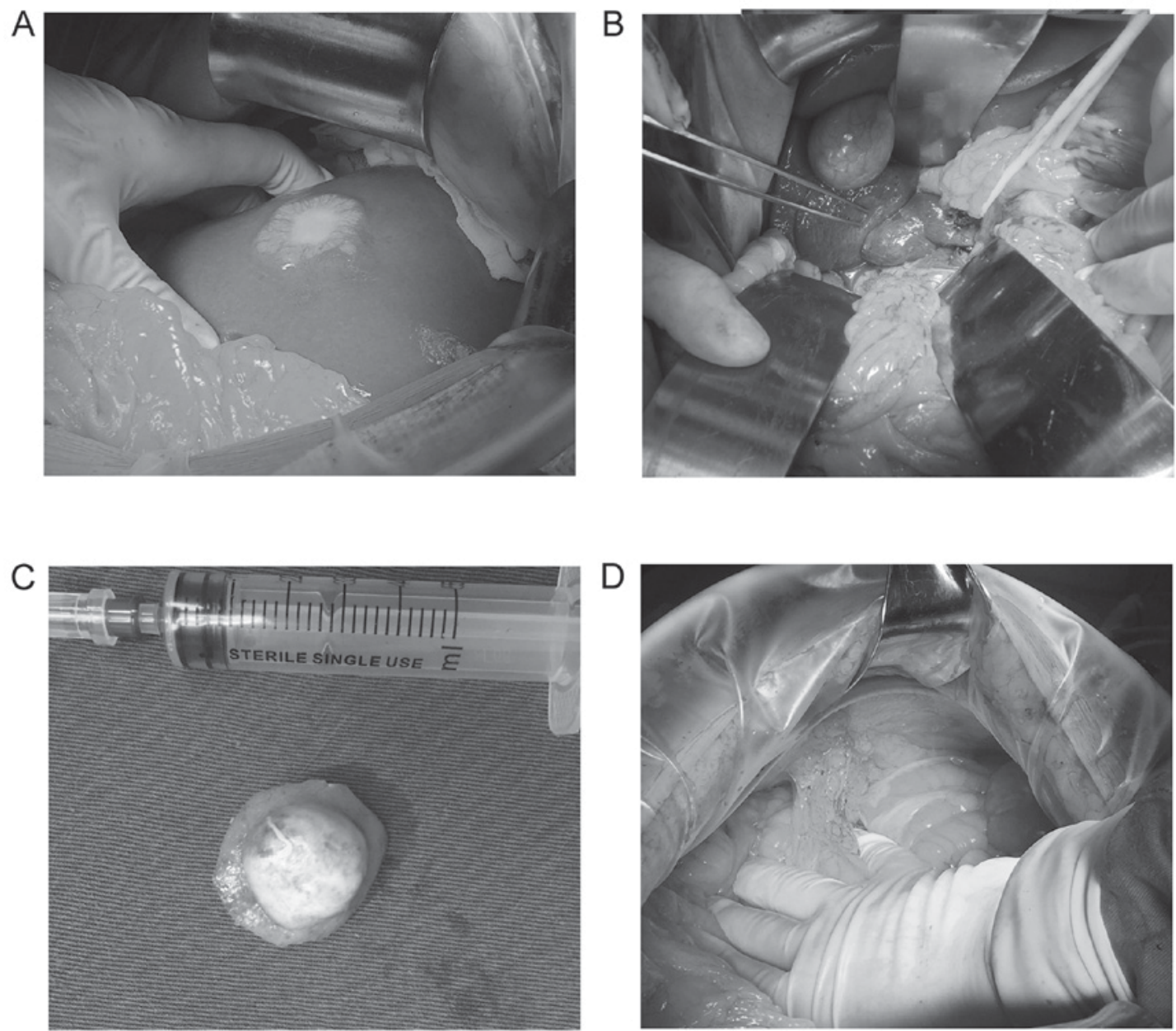

Figure 4. Peri-operative images. (A) A round yellow-white mass located in the right anterior lobe of the liver; (B) $4 \mathrm{~cm}$ diameter round protruding lesion on the liver surface located in the VII segment; (C) $\sim 2 \mathrm{~cm}$ diameter round lesion excised from the right kidney; (D) The location of a right abdomen wall of adhesion corresponding to the area of slight hypo-metabolism indicated by positron emission tomography-computed tomography.

$\alpha v \beta 6$ in thyroid papillary carcinoma to be $79.03 \%(49 / 62)$ $78.57 \%(22 / 26)$ in thyroid follicular carcinoma, and $100 \%$ in metastatic lymph nodes (10/10) (30). Combined with additional previous data, it was proposed that integrin $\alpha v \beta 6$ may have an important role in MPC.

Renal clear cell carcinoma (RCC) originates from the malignant transformation of renal tubular epithelial cells. Due to its expression in malignant epithelial tumors, integrin $\alpha v \beta 6$ may also be expressed in RCC. However, in this patient study, RCC specimens were negative for integrin $\alpha v \beta 6$ expression, supported by the lack of literature reporting integrin $\alpha v \beta 6$ expression in RCC tissue. Negative expression is predicted to be due to the loss of cytoplasm from RCC carcinoma cells during the preparation of the tissue sections. The loss of lipid components and vacuolization of the cytoplasm forms the so-called 'transparent' component; as integrin $\alpha v \beta 6$ is predominantly expressed in the epithelial cell membrane and cytoplasm, cytoplasmic depletion in RCC may potentially negate the expression of integrin $\alpha v \beta 6$.

The incidence of MPC is increasing, thus there is an urgent need to develop the understanding of MPC pathogenesis, diagnosis and treatment. Current treatment regimens for MPC differ from those indicated for traditional recurrent or metastatic malignant tumors. For MPC, radical excision of the tumors is preferred. When faced with that for recurrent or metastatic malignant tumors, the prognosis for MPC is comparatively more favorable $(31,32)$.

With improvements in anti-tumor treatment technology, the prognosis for tumor patients has improved, though there has been a corresponding rise in the incidence of MPC. The aim of the clinician should be to improve understanding of MPC, reduce misdiagnosis and missed diagnosis, make early diagnoses to facilitate earlier treatment, and to administer radical surgery, radiotherapy and chemotherapy, and targeted therapy to improve clearance rates and prolong patient survival. The current case demonstrates that integrin $\alpha v \beta 6$ is positively expressed in MPC. Combined with previous research, this may implicate integrin $\alpha v \beta 6$ in the pathogenesis of MPC, and aid future research into the etiology of MPC.

\section{Acknowledgements}

Not applicable.

\section{Funding}

This study was supported by the Natural Sciences Foundation of Shandong Province (grant no. ZR2015HM042). 


\section{Availability of data and materials}

The datasets used and/or analyzed during the current study are available from the corresponding author on reasonable request.

\section{Authors' contributions}

CP led patient diagnosis and treatment, and manuscript authorship. ZL performed the immunohistochemical staining. $\mathrm{HG}$, was the resident carer, responsible for the daily care of the patient, recorded the clinical laboratory examination results, and retrieved the related literature. XZ was responsible for data collation, statistical analysis and figure creation. XW was responsible for pathological procedures and diagnoses. CZ performed the radical nephrectomy. JN as the chief surgeon, performed the radical resection of sigmoid colon cancer and excision of liver metastases from sigmoid colon cancer. He was additionally involved the immunohistochemical staining experiment and statistical analysis of data. As the Dean of the Institute of Laparoscopic Minimally Invasive Surgery of Shandong University, he gave the final approval of the article.

\section{Ethics approval and consent to participate}

Not applicable.

\section{Patient consent for publication}

The patient provided informed consent for the use of the data in this study.

\section{Competing interests}

The authors declare that they have no competing interests.

\section{References}

1. Ueno M, Muto T, Oya M, Ota H, Azekura K and Yamaguchi T: Multiple primary cancer: An experience at the Cancer Institute Hospital with special reference to colorectal cancer. Int J Clin Oncol 8: 162-167, 2003.

2. Demandante CG, Troyer DA and Miles TP: Multiple primary malignant neoplasms: Case report and a comprehensive review of the literature. Am J Clin Oncol 26: 79-83, 2003.

3. Jones AS, Morar P, Phillips DE, Field JK, Husband D and Helliwell TR: Second primary tumours in patients with head and neck squamous cell carcinoma. Cancer 75: 1343-1353, 1995.

4. Aydiner A, Karadeniz A, Uygun K, Tas S, Tas F, Disci R and Topuz E: Multiple primary neoplasms at a single institution: Differences between synchronous and metachronous neoplasms. Am J Clin Oncol 23: 364-370, 2000.

5. Ries LA, Eisner MP, Kosary CL, Hankey BF, Miller BA and Clegg L (eds): SEER Cancer Statistics Review. 1975-2000. National Cancer Institute, Bethesda, MD, 2003.

6. Jiao F, Hu H and Wang LW: Quadruple primary malignancy patient with survival time more than 20 years. World J Gastroenterol 19: 1498-1501, 2003.

7. Jones P: Five separate malignancies in one patient. Br Med J 1: 1533, 1976.

8. Shankar PS: Case report. Five primary cancers in one patient Postgrad Med 61: 281-282, 1977.

9. Liu LY, Sheng SH, Zhang ZY and Xu JH: A case of matrix-producing carcinoma of the breast with micoglandular adenosis and review of literature. Int J Clin Exp Pathol 8 : 8568-8572, 2015.

10. Ye Y, Neil AL, Wills KE and Venn AJ: Temporal trends in the risk of developing multiple primary cancers: A systematic review. BMC Cancer 16: 849, 2016.
11. Baigrie RJ: Seven different primary cancers in a single patient. A case report and review of multiple primary malignant neoplasia. Eur J Surg Oncol 17: 81-83, 1991.

12. Curtis RE, Freedman DM, Ron E, Ries LAG, Hacker DG, Edwards BK, Tucker MA and Fraumeni Jr JF: New malignancies among cancer survivors: SEER cancer registries, 1973-2000. National Cancer Institute, Bethesda, MD, NIH Publ. No. 05-5302. 2006.

13. Linet MS, Slovis TL, Miller DL, Kleinerman R, Lee C, Rajaraman P and Berrington de Gonzalez A: Cancer risks associated with external radiation from diagnostic imaging procedures. CA Cancer J Clin 62: 75-100, 2012.

14. Meyerhardt JA, Mangu PB, Flynn PJ, Korde L, Loprinzi CL, Minsky BD, Petrelli NJ, Ryan K, Schrag DH, Wong SL, et al: Follow-up care, surveillance protocol, and secondary prevention measures for survivors of colorectal cancer: American society of clinical oncology clinical practice guideline endorsement. J Clin Oncol 31: 4465-4470, 2013.

15. Mathews JD, Forsythe AV, Brady Z, Butler MW, Goergen SK, Byrnes GB, Giles GG, Wallace AB, Anderson PR, Guiver TA, et al: Cancer risk in 680000 people exposed to computed tomography scans in childhood or adolescence: Data linkage study of 11 million Australians. BMJ 346: f2360, 2013.

16. Kim C, Bi X, Pan D, Chen Y, Carling T, Ma S, Udelsman R and Zhang Y: The risk of second cancers after diagnosis of primary thyroid cancer is elevated in thyroid microcarcinomas. Thyroid 23: 575-582, 2013.

17. Morgan DJ, Dhruva SS, Wright SM and Korenstein D: Update on medical practices that should be questioned in 2015. JAMA Intern Med 175: 1960-1964, 2015.

18. Davies L and Welch HG: Increasing incidence of thyroid cancer in the United States, 1973-2002. JAMA 295: 2164-2167, 2006.

19. Matesich SM and Shapiro CL: Second cancer after breast cancer treatment. Semin Oncol 30: 740-748, 2003.

20. Williams-Brown MY, Salih SM, Xu X, Veenstra TD, Saeed M, Theiler SK, Diaz-Arrastila CR and Salama SA: The effect of tamoxifen and raloxifene on estrogen metabolism and endometrial cancer risk. J Steroid Biochem Mol Biol 126: 78-86, 2011.

21. Breuss JM, Gillett N, Lu L, Sheppard D and Pytela R: Restricted distribution of integrin beta $6 \mathrm{mRNA}$ in primate epithelial tissue. J Histochem Cytochem 41: 1521-1527,1999.

22. Breuss JM, Gallo J, DeLisser HM, Klimanskaya IV, Folkesson HG, Pittet JF, Nishimura SL, Aldape K, Landers DV, Carpenter W, et al: Expression of the beta 6 integrin subunit in development, neoplasia and tissue repair suggests a role in epithelial remodeling. J Cell Sci 108: 2241-2251, 1995.

23. Bates RC, Bellovin DI, Brown C, Maynard E, Wu B, Kawakatsu H, Sheppard D, Oettgen P and Mercurio AM: Transcriptional activation of integrin beta 6 during the epithelial-mesenchymal transition defines a novel prognostic indicator of aggressive colon carcinoma. J Clin Invest 115: 339-347, 2005.

24. Zhang ZY, Xu KS, Wang JS, Yang GY, Wang W, Wang JY, Niu WB, Liu EY, Mi YT and Niu J: Integrin alpha v beta 6 acts as a prognostic indicator in gastric carcinoma. Clin Ongol 20: 61-66, 2008.

25. Niu J, Gu X, Turton J, Meldrum C, Howard EW and Agrez M: Integrin-mediated signalling of gelatinase B secretion in colon cancer cells. Biochem Biophys Res Commun 249: 287-291, 1998.

26. Agrez M, Gu XH, Turton J, Meldrum C, Niu J, Antalis T and Howard EW: The alpha $\mathrm{v}$ beta 6 integrin induces gelatinase $\mathrm{B}$ secretion in colon cancer cells. Int J Cancer 81: 90-97, 1999.

27. Yang GY, Xu KS, Pan ZQ, Zhang ZY, Mi YT, Wang JS, Chen R and Niu J: Integrin alpha v beta 6 mediates the potential for colon cancer cells to colonize in and metastasize to the liver. Cancer Sci 99: 879-887, 2008

28. Liu S, Wang J, Niu W, Liu E, Wang J, Peng C, Lin P, Wang B, Khan AQ, Gao H, et al: The $\beta 6$-integrin-ERK/MAP kinase pathway contributes to chemo resistance in colon cancer. Cancer Lett 328: 325-334, 2013

29. Yang GY, Xu KS, Pan ZQ, Zhang ZY, Mi YT, Wang JS, Chen R and Niu J: Integrin alpha $v$ beta 6 mediates the potential for colon cancer cells to colonize in and metastasize to the liver. Cancer Sci 99: 879-887, 2008.

30. Liu S, Liang B, Gao H, Zhang F, Wang B, Dong X and Niu J: Integrin $\alpha v \beta 6$ as a novel marker for diagnosis and metastatic potential of thyroid carcinoma. Head Neck Oncol 5: 7, 2013.

31. Koide N, Adachi W, Koike S, Watanabe H, Yazawa K and Amano J: Synchronous gastric tumors associated with esophageal cancer: A retrospective study of twenty-four patients. Am J Gastroenterol 93: 758-762, 1998.

32. Chai W, Gong FY, Zhang WL, Wen Y and Cui LF: Multiple primary cancer in the female genital system. Medicine 96: 47, 2017. 